data. Through structuring and central data registration, a Germany-wide unique service of TIB, valuable knowledge will be harnessed.

"The data will be permanently saved and, by assigning them a DOI, made accessible and searchable, as well as citable and linkable," states Jan Brase from the TIB Registration Agency. An additional positive effect is that authors receive recognition for their research work.

www.thieme-connect.com/ejournals

\section{In Memoriam: Pan Ming Huang (1934-2009)}

\section{by Antonio Violante}

\section{r}

ongtime IUPAC member Pan Ming Huang, professor emeritus of soil science at the University of Saskatchewan, Saskatoon, Canada, died 13 September 2009 at age 75.

Huang was an eminent scholar, a great educator, a man of vision, and extraordinary leadership. $\mathrm{He}$ was a teacher appreciated for his organization and thoroughness, his passion for science, and for his high expectations. Most of his students and colleagues mention the decisive influence he had on their careers. A member of the IUPAC Chemistry and the Environment Division Committee, the Subcommittee on Biophysico-Chemical Processes in Environmental Systems, and earlier of the Commission on Fundamental Environmental Chemistry, Huang was editor of the IUPAC book series Biophysico-Chemical Processes in Environmental Systems.

Huang was born in Taiwan on 2 September 1934. After graduating with a degree in agricultural chemistry from the National Chung Hsing University, he moved to the University of Manitoba, Winnipeg, in 1961. It was there that he met Lin, the lovely young woman who was to become his wife. He moved on to the University of Wisconsin at Madison upon completing his Masters in 1962, studying for his Ph.D. with M.L. Jackson, one of the world's most highly regarded soil scientists. Huang and Jackson worked well together, developing a warm friendship that continued for decades. Huang received his Ph.D. degree in Soil Science in 1965 and in the same year traveled to Saskatoon having accepted a position in the Department of Soil Science at the University of Saskatchewan. In 1966, he and Lin were married. Lin has been a wonderful companion and support for him. They have two children: Daniel and Crystal.

Huang was a leading international authority on environmental soil chemistry, with emphasis on mineral colloids and organo-mineral complexes, their reactions with nutrients and pollutants in soils and waters and the impact on ecosystem health. He pioneered extensive chemical, spectroscopic, and ultramicroscopic research on the formation mechanisms of short-range ordered (poorly crystalline) mineral colloids which are extremely reactive in governing the accumulation, transport, and bioavailability of nutrients and pollutants in the environment. He performed groundbreaking work in establishing mineral catalysis mechanisms of transformations of biomolecules such as sugars, phenolic compounds and amino acids, and the resulting formation of humic substances which are essential for maintaining and for enhancing the productivity of the land and are also vital in influencing the dynamics and fate of environmental pollutants. Further, his cutting-edge research has advanced the world's knowledge on the chemistry and behavior of vital and toxic inorganic ions and organic compounds in soils and freshwaters and their impact on agricultural sustainability and ecosystem protection.

His research accomplishments are embodied in over 300 refereed publications, of which nine were published in Nature. Furthermore, he has written 2 books, edited 17 books, and successfully trained and inspired Ph.D. and M.Sc. students (more than 60) and postdoctoral fellows (45).

\section{Errata}

On page 7 in the Nov-Dec 2009 Cl, a caption identifying IUPAC Vice President Kazuyuki Tatsumi of Japan is mislabeled and incorrectly lists his country as Korea.

On page 22 in the Nov-Dec 2009 Cl (last paragraph) it is mentioned that Maximo Baron was accepted as a fellow by The Royal Society of London. This is a mistake and should simply read that he is a Fellow of The Royal Society of Chemistry. 